\title{
We Are Not a Specialty - Should We Be?
}

Jean-François Masse, DMD, MSc, FACD, Diplomate, ABDSM

Editor-in-Chief Journal of Dental Sleep Medicine

Universite Laval, Quebec City, Quebec, Canada

The ADA recognized orofacial pain (OFP) as dentistry's twelfth specialty on March 31 st of this year. ${ }^{1}$ This is quite an achievement, and I would like to congratulate the American Academy of Orofacial Pain (AAOP) members for their hard work. An OFP colleague told me they had been talking about becoming a specialty for 20, if not more years.

Over the years, I have had the chance to discuss many times with members of the American Academy of Dental Sleep Medicine (AADSM) about dental sleep medicine (DSM) becoming a dental specialty. I feel we will hear more and more about this, especially if we get a chance to meet in Chicago in 2021. So, should DSM become a specialty? Some may think that the question is premature, with DSM being a promising, but relatively new field.

There has always been a peculiar aura around a specialty status, and some could argue that a DSM specialty could increase the credibility of the field. Some may advocate that we, as a DSM community, would be better off being considered as a subspecialty. In medicine, sleep and pain are subspecialties. Sleep medicine requires a 12-month fellowship. They have had a difficult time filling their programs. ${ }^{2}$ In 2019 , there was a decrease in the number of board-certified sleep medicine physicians. ${ }^{3}$ Is there something to be learned from this?

Looking at what is being offered by dental programs regarding sleep, we realize that our field is indeed in its infancy. If we compare what we have to the thirteen CODA -accredited programs in orofacial pain, ${ }^{4}$ one can see there is a long way to go before we get to this level of academic presence. Teaching DSM at universities is a challenge, but any dentist doing it will tell you that the situation is quickly and steadily improving. Interestingly, there are two good papers on education in this issue. I invite you to have a look at them.

Another aspect to consider is the requirement of two-year training program for any dental specialty. Does DSM require two years of training? The ADA has indicated that continuing education is enough to provide oral appliance therapy. ${ }^{5}$ The AADSM's Mastery Program provides 65 hours. ${ }^{6}$ Perhaps as the field evolves, the requirements for dental sleep medicine training will expand. Two years of education is a big commitment in terms of both time and money. With an average debt of
\$292,169 upon finishing dental school, ${ }^{7}$ higher education is not within the reach of everyone.

One final aspect to consider is the sheer numbers of those with sleep apnea. Does specialty status help the 54 million Americans with sleep apnea? ${ }^{8}$

If anyone hoped for a definitive answer to the question asked in the title of this editorial, I am sorry. Your answer is as good as anyone else's. But this topic will certainly evolve as more discussions are being held.

Only the future will tell us if DSM will become a specialty. In the meantime, we need to take steps to ensure that those 54 million Americans are helped. We cannot afford to wait and see. To become proficient in the treatment of those patients, I encourage you to invest your energy on staying informed by first reading the HSAT position statement and the therapeutic positioning paper in this JDSM issue. Much has changed in the sleep field recently, and I applaud the leadership of the AADSM for being proactive, not reactive.

As it seems that the activity in dental offices is getting closer to pre-COVID levels, ${ }^{9}$ let us just hope for a rapid resolution of the pandemic, allowing us to focus on helping people with sleep problems.

\section{CITATION}

Masse, JF. We are not a specialty - Should we be?. J Dent Sleep Med. 2020;7(4)

\section{REFERENCES}

1. Press release: Orofacial pain is now the 12th ADA-recognized dental specialty. American Academy of Orofacial Pain. April 20, 2020. Accessed October $\quad 8, \quad 2020$ https://aaop.clubexpress.com/content.aspx?page_id=22\&club_id= 508439\&module_id=107327

2. ABMS board certification report: 2018-2019. 2019. Accessed October 8, 2020. https://abms.org/media/257753/abms-boardcertification-report-2018-2019.pdf

3. Results and data: Specialty services matching. National Resident Matching Program.2020. Accessed October 8, 2020. https://mk0nrmp3oyqui6wqfm.kinstacdn.com/wpcontent/uploads/2020/02/Results-and-Data-SMS-2020.pdf

4. Orofacial Pain Programs in the US \& Canada. American Academy of Orofacial Pain. Accessed October 8, 2020. https://aaop.clubexpress.com/content.aspx?page_id=22\&club_id= 508439\&module_id $=107337$

5. Burger D. Sleep-related breathing disorder treatment outlined in 
new policy. American Dental Association. October 31, 2017. Accessed October 8, 2020. https://www.ada.org/en/publications/adanews/2017-archive/october/sleep-related-breathing-disordertreatment-outlined-in-new-policy

AADSM Mastery Program. American Academy of Dental Sleep Medicine. October 8, 2020. https://www.aadsm.org/aadsm_mastery_program.php

7. Educational Debt. American Dental Education Association. Accessed October 8, 2020. https://www.adea.org/GoDental/Money_Matters/Educational_Debt.aspx

8. Benjafield et al. Estimation of the global prevalence and burden of obstructive sleep apnoea: a literature-based analysis. Lancet Respir Med 2019 Aug;7(8):687-698

9. Versaci MB. HPI poll: Dentists see increase in patients' stress-related oral health. American Dental Association. September 28, 2020. Accessed October 8, 2020. https://www.ada.org/en/publications/ada-news/2020-archive/september/hpi-poll-dentists-see-increase-in-patients-stress-related-oral-health-conditions

\section{SUBMISSION AND CORRESPONDENCE INFORMATION}

Submitted in final revised form October 8, 2020.

Address correspondence to: Jean-François Masse, DDS, MSc, FACD, D.ABDSM, Professor, Universite Laval, 2780 Masson \#200, Quebec City, QC, G1P 1J6, Canada; Tel: 418871-1447; Fax: 418-871-4983; Email: jean-francois.masse@fmd.ulaval.ca 